ournal of Back and Musculoskeletal Rehabilitation

\title{
'Call for Papers'
}

\section{Journal of Back and Musculoskeletal Rehabilitation}

The Journal of Back and Musculoskeletal Rehabilitation is now being published 6 times per year!

Due to this expansion, we are now accepting submission of original research, case studies, program descriptions, and review articles for publication in the Journal.

Some issues will continue to cover specific topics with a Guest Editor, however, other issues will now cover a variety of topics in the area of back and musculoskeletal rehabilitation, compiled from manuscripts received at the JBMR office.

Aim and Scope: The Journal of Back and Musculoskeletal Rehabilitation is a journal whose main focus is to present information about musculoskeletal rehabilitation to clinicians who treat patients with back and musculoskeletal pain complaints. Its goal is to provide readers with (1) a general fund of knowledge on the assessment and management of specific problems and (2) new information considered to be state-of-the-art in the field. The intended audience is multi-disciplinary as well as multi-specialty.

Manuscripts are provided from a wide range of health care specialties including physical medicine, orthopedic surgery, rheumatology, neurosurgery, physical therapy, radiology, osteopathy, chiropractic and nursing. Topics range from chronic pain to sports medicine.

Please submit original plus three copies along with computer disk to:

Karen S. Rucker, MD

Editor-in-Chief, JBMR

Chair and Associate Professor

Department of Physical Medicine \& Rehabilitation

$\mathrm{VCU} /$ Medical College of Virginia

PO Box 980677, 1223 East Marshall Street

Richmond, VA 23298

Phone: 804-828-0474/Fax: 804-828-6340

(See Instructions to Authors for more information on submitting manuscripts.)

*As the Journal continues to seek to meet your needs, we encourage your suggestions on topics and new sections that you would like to see published in the Journal. 